\title{
Towards agricultural soil carbon monitoring, repo
verification through Field Observatory Network (FiON)
}

\author{
Olli Nevalainen ${ }^{1}$, Olli Niemitalo ${ }^{2}$, Istem Fer ${ }^{1}$, Antti Juntunen ${ }^{2}$, Tuomas Mattila ${ }^{3}$, Olli Koskela ${ }^{2}$, Joni \\ Kukkamäki ${ }^{2}$, Layla Höckerstedt ${ }^{1}$, Laura Mäkelä ${ }^{4}$, Pieta Jarva ${ }^{4}$, Laura Heimsch ${ }^{1}$, Henriikka Vekuri ${ }^{1}$, Liisa \\ Kulmala ${ }^{1,5}$, Åsa Stam ${ }^{1}$, Otto Kuusela ${ }^{1,6,7}$, Stephanie Gerin ${ }^{1}$, Toni Viskari ${ }^{1}$, Julius Vira ${ }^{1}$, Jari Hyväluoma ${ }^{2}$, \\ Juha-Pekka Tuovinen ${ }^{1}$, Annalea Lohila ${ }^{1,6}$, Tuomas Laurila ${ }^{1}$, Jussi Heinonsalo ${ }^{5}$, Tuula Aalto ${ }^{1}$, Iivari \\ $\mathrm{Kunttu}^{2}$, Jari Liski ${ }^{1}$
}

${ }^{1}$ Finnish Meteorological Institute, FMI, Helsinki, Finland

${ }^{2}$ Häme University of Applied Sciences, HAMK, Hämeenlinna, Finland

${ }^{3}$ Finnish Environment Institute, SYKE, Helsinki, Finland

${ }^{4}$ Baltic Sea Action Group, BSAG, Espoo, Finland

${ }^{5}$ University of Helsinki, Institute for atmospheric and Earth system research (INAR), forest sciences, Helsinki, Finland

${ }^{6}$ University of Helsinki, Institute for atmospheric and Earth system research (INAR), physics, Helsinki, Finland

${ }^{7}$ University of Amsterdam, Computational Science, Amsterdam, Netherlands

Correspondence to: (olli.nevalainen@fmi.fi)

Abstract. Better monitoring, reporting and verification (MRV) of the amount, additionality and persistence of the sequestered soil carbon is needed to understand the best carbon farming practices for different soils and climate conditions, as well as their actual climate benefits or cost-efficiency in mitigating greenhouse gas emissions. This paper presents our Field Observatory Network (FiON) of researchers, farmers, companies and other stakeholders developing carbon farming practices. FiON has established a unified methodology towards monitoring and forecasting agricultural carbon sequestration by combining offline and near real-time field measurements, weather data, satellite imagery, modeling and computing networks. FiON's first phase consists of two intensive research sites and 20 voluntary pilot farms testing carbon farming practices in Finland. To disseminate the data, FiON built a web-based dashboard called Field Observatory (v1.0, fieldobservatory.org). Field Observatory is designed as an online service for near real-time model-data synthesis, forecasting and decision support for the farmers who are able to monitor the effects of carbon farming practices. The most advanced features of the Field Observatory are visible on the Qvidja site which acts as a prototype for the most recent implementations. Overall, FiON aims to create new knowledge on agricultural soil carbon sequestration and effects of carbon farming practices, and provide an MRV tool for decision-support. 
Geoscientific Instrumentation Methods and Data Systems

Discussions

\section{Introduction}

Farmers are managing one of the largest carbon stocks on the planet where even relatively small additions are important for climate change mitigation. Accordingly, the international "soil carbon 4 per mille" initiative aims at raising the soil organic carbon content by $0.4 \%$ per year by adopting carbon farming practices (Minasny et al. 2017). Carbon farming practices include methods, such as reduced soil disturbance (reduced or zero tillage), increasing carbon inputs (soil amendments, cover crops, residue management) and crop rotations. Such practices do not only have the potential to partially refill the global soil carbon stock that has lost 116 Pg carbon due to land cultivation (Sanderman et al., 2017), but they could also improve soil structure and health, and increase crop yields (Merante et al. 2017; Oldfield et al. 2018). Annual carbon sequestration rates for different

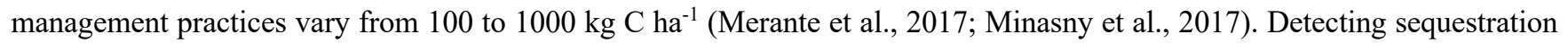
rates in this range is difficult with traditional empirical soil sampling designs due to large spatial variability of soil carbon content and small relative changes in the soil carbon stock due to individual management actions (VandenBygaart and Angers 2006; Heikkinen et al. 2021). This calls for better monitoring, reporting and verification (MRV) of the amount, additionality and persistence of the sequestered soil carbon due to carbon farming practices.

Towards this goal, we established the Field Observatory Network (FiON), a network of researchers, farmers, companies and other stakeholders applying carbon farming practices. FiON has created a unified methodology to monitor and forecast agricultural carbon sequestration, by combining automated near real-time field measurements, weather data, satellite imagery, modeling and computing networks. In general, FiON follows the principles of other ecological observatory networks, such as National Ecological Observatory Network (NEON, Keller et al., 2008), Global Lake Ecological Observatory Network (GLEON, Hipsey et al., 2017) and Biodiversity Observatory Networks (GEOBON, Guerra et al., 2021) that collect long-term ecological data and monitor the effects of climate and land use change (Elmendorf 2016; Hinckley et al., 2016; Hipsey et al., 2017; Keller et al., 2008). The primary purpose of FiON, however, is to i) create new knowledge on soil processes, ii) to measure, verify and forecast the carbon sequestration in agricultural soils and to iii) approximate the effects of carbon farming practices on yield, biomass and $\mathrm{CO}_{2}$ flux in near real-time. To achieve this, FiON invested in the use and development of a community cyberinfrastructure tool, Predictive Ecosystem Analyzer (PEcAn, pecanproject.org), which enables synthesizing different data sources and process-based models, quantifying and partitioning uncertainties, and operationalizing near realtime ecological forecasting (Fer et al., 2021). To disseminate the observations and findings, we built a free-access online dashboard called Field Observatory (v1.0, fieldobservatory.org). This website serves as a tool to monitor the impacts of carbon farming practices. The dashboard integrates data from field sensors, remote sensing and field survey. In this sense, FiON will provide decision support for the farmers, at first hand via the Field Observatory website and in due course via the scientific synthesis informed by the best available data and models. To serve the research and other interested communities, the data in Field Observatory is publicly available and downloadable from the website. 
In this paper our objectives are to 1) describe data flows from various manual and automatic measurements in the Field observatory, 2) demonstrate 15-day forecasts of carbon exchange and plant growth towards decision support for the farmers, and 3) discuss the benefits of the public monitoring network established by FiON.

First, we introduce the sites included in FiON, and describe the tested carbon farming practices. Next, we describe the FiON workflow from data collection, processing and storage to visualization and dissemination through the Field Observatory website. Finally, we present the near real-time model-data synthesis, forecasting and decision support for the users.

\section{Sites and tested carbon farming practices}

The first phase of FiON consists of two intensive agricultural research sites and 20 voluntary farms testing carbon farming practices (Fig. 1, https://www.fieldobservatory.org/MapView). These 20 farms, called Advanced Carbon Action farms (ACA), were selected out of 100 pilot farms participating in the Carbon Action platform ${ }^{1}$, where volunteer farmers test carbon farming practices (Mattila et al. 2021). Each farm has a test field and an adjacent, conventionally managed, control field (field 1 and 0 in Field Observatory, respectively). The additional carbon farming practices aim to increase carbon sequestration through increasing photosynthesis, exogenous inputs or through decreasing decomposition (Minasny et al., 2017). These practices (Table 1) are: cover crops, adaptive grazing, soil amendments, subsoiling and ley farming (introducing a grass crop into rotation). Each farmer made a five-year carbon farming plan and took soil samples at the beginning of the study from GPS located points in the field. The same points are monitored annually and also contain real-time soil sensors.

Carbon Action platform consists of several scientific projects, 100 farms committed to 5 years of research activity and farmer extension services. As of spring 2021, some 600 farmers are participating around the topic. Food system companies and organisations are also involved. Carbon Action is led by BSAG and the research is coordinated by FMI. More https://carbonaction.org/en/front-page/ 
https://doi.org/10.5194/gi-2021-21

Preprint. Discussion started: 2 August 2021

(c) Author(s) 2021. CC BY 4.0 License.

(c) (i)

Geoscientific Instrumentation

Methods and

Data Systems

Discussions

Table 1 Principles of the carbon farming practices tested at the Carbon Action farms.

\begin{tabular}{|c|c|}
\hline Carbon farming practice & Principles for carbon sequestration \\
\hline Cover crops & $\begin{array}{c}\text { Crops planted to lengthen photosynthetically active period and to increase } \\
\text { carbon assimilation, carbon and root inputs and to reduce leaching of carbon } \\
\text { and nutrients. }\end{array}$ \\
\hline Adaptive grazing & $\begin{array}{l}\text { Short grazing \& long rest periods to manage grass growth for increased root } \\
\text { growth and increased soil cover. }\end{array}$ \\
\hline Soil amendments & $\begin{array}{l}\text { Exogenous carbon input. In addition may stimulate plant growth through } \\
\text { increased water holding capacity, nutrients, etc. }\end{array}$ \\
\hline Subsoiling & $\begin{array}{l}\text { Removing physical barriers to root growth by soil loosening. Coupled to a grass } \\
\text { crop to stabilize loosened soil. Increases plant growth and soil aeration and } \\
\text { decreases bulk density. }\end{array}$ \\
\hline Ley farming & $\begin{array}{l}\text { Breaking monocropping with perennial grass. Increases photosynthesis, root } \\
\text { input and diversity. }\end{array}$ \\
\hline Grass cultivation & $\begin{array}{l}\text { Diverse plant species composition, increased cutting height and organic } \\
\text { fertilization. }\end{array}$ \\
\hline
\end{tabular}

84

The 20 ACA farms were selected based on their chosen practice (four farms per measure), location (appropriate distances for survey work and even spread over Finnish farmland) and soil type (a mix of clay and sandy soils) (Table 2). All of them were included in a soil condition survey in 2019 (Mattila, 2020). Farms with anomalous measurements or too large organic matter content or nutrient differences between the control and treatment plots in the initial phase of FiON were excluded from ACA farms. FiON includes two intensive research sites, Qvidja and Ruuukki, which are operated by the Finnish Meteorological Institute (FMI). In Qvidja, carbon farming practices are tested in three different fields. In Ruukki, there are no carbon farming practices implemented at the moment. Both sites have eddy covariance towers which continuously monitor greenhouse gas fluxes and weather(see Sect. 3). 

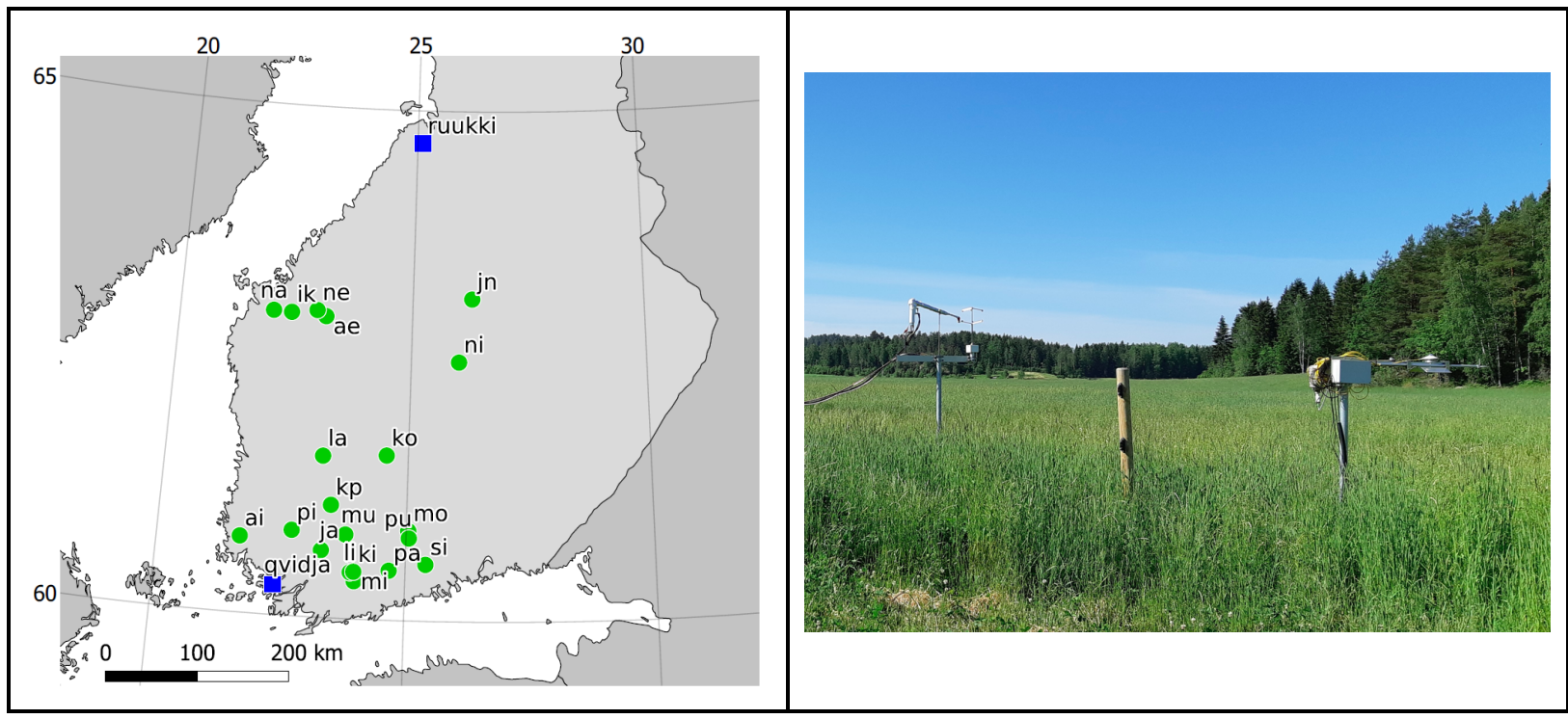

Figure 1 Map of Advanced Carbon Action sites (green dots) and intensive sites (blue squares) (left), and eddy covariance

Table 2 Current FiON sites.

\begin{tabular}{cccccc}
\hline Site & Site type & Soil type & $\begin{array}{c}\text { Carbon farming } \\
\text { practice }\end{array}$ & Species in 2020 & Nearest FMI weather station \\
\cline { 1 - 1 } AE & ACA & Sandy loam & Subsoiling & Rye & Kauhava airport \\
KO & ACA & Silt & Subsoiling & Silage grass & Juupajoki Hyytiälä \\
KP & ACA & Clay loam & Subsoiling & Multi-species ley & Pirkkala airport \\
LA & ACA & Clay silt & Subsoiling & Oats & Pirkkala airport \\
JN & ACA & Fine sand & Adaptive grazing & Pasture grass & Vesanto Sonkari \\
MI & ACA & Clay loam & Adaptive grazing & Pasture grass & Lohja Porla \\
NI & ACA & Sand till & Adaptive grazing & Pasture grass & Jyväskylä airport AWOS \\
KI & ACA & Fine sand & Soil amendments & Multi-species ley & Somero Salkola \\
LI & ACA & Clay loam & Soil amendments & Spring wheat & Lohja Porla \\
PA & ACA & Clay loam & Soil amendments & Hay grass & Nurmijärvi Röykkä
\end{tabular}


Geoscientific Instrumentation Methods and Data Systems

Discussions

\section{Kaarina Yltöinen}

Somero Salkola

Vaasa airport

Kauhava airport

NE $\quad$ ACA

Loam

Cover crops

Oats

Mäntsälä Hirvihaara

PU

ACA Silty clay loam

Cover crops

Oats

Porvoo Harabacka

SI

ACA

Clay loam

Cover crops

Multi-species ley

Ley farming

Multi-species ley

Ley farming

Multi-species ley

Silage grass

Sand till

Ley farming

Ley farming

Barley

Silage grass

Silage grass
Rauma Pyynpää

Jokioinen IImala

Seinäjoki Pelmaa

Hämeenlinna Lammi Pappila

Kaarina Yltöinen*

Siikajoki Ruukki*

\section{Data collection}

FiON combines multiple online and offline data streams with different temporal frequencies and geographical extent (Fig. 2,

Table 3). These data streams flow into a server where the data are pre-processed (filtered, gap-filled, formatted) and modeldata analyses are performed through an ecological cyberinfrastructure Predictive Ecosystem Analyzer (PEcAn, Fer et al., 2021). All observational and computational outputs are stored in the server and disseminated through a web-based user interface. In the following sections we describe each data stream and model-data activity in the order given in Fig. 2. 


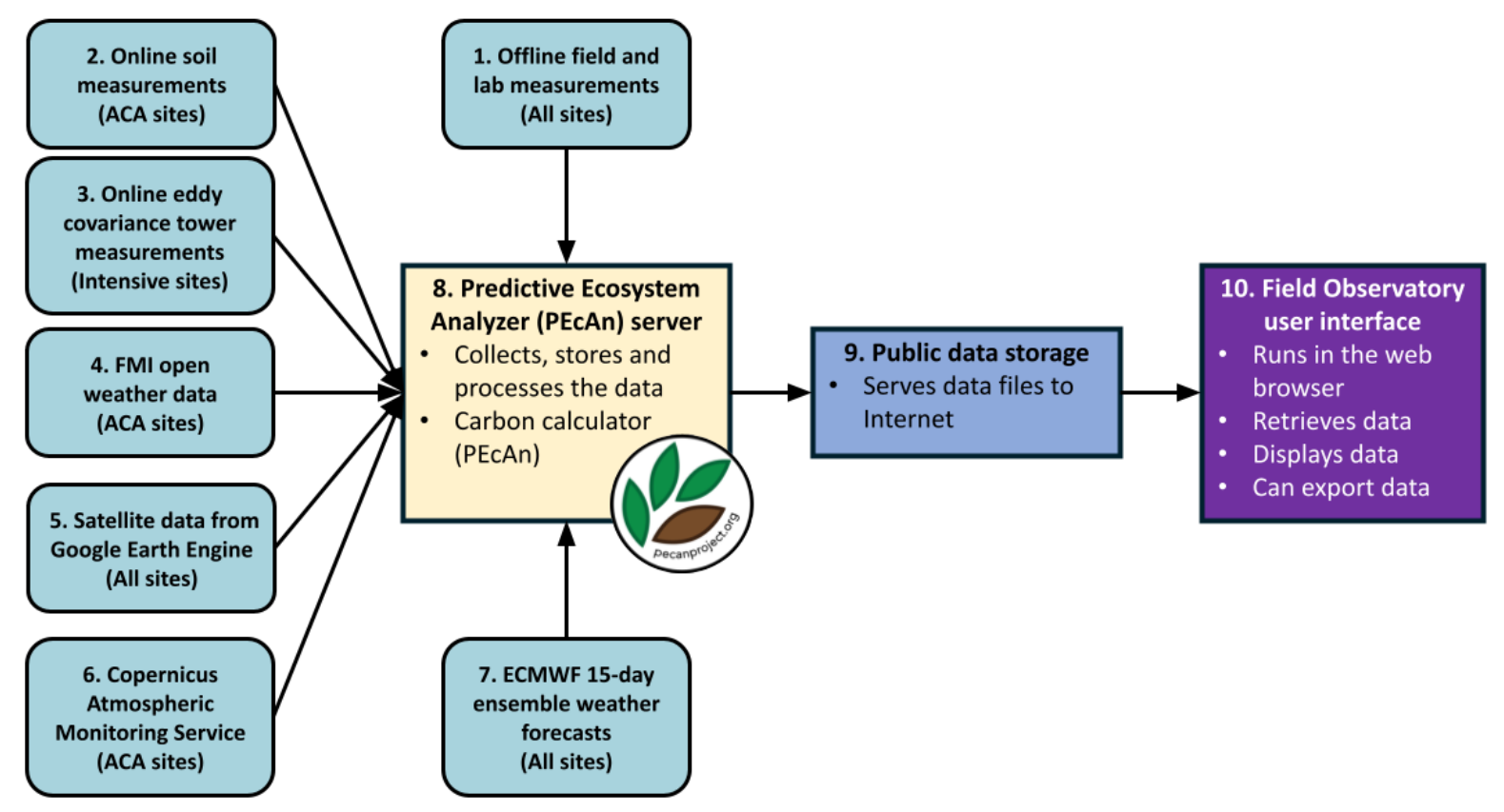

Figure 2 Overview of the FiON data flows.

\subsection{Offline field and lab measurements}

At ACA sites, the measurements are done at three, static measurement points per field. The points have c.a. 30-100 m distance from each other and are located on a transect line. They were located to cover the variability of the field and cover similar soil conditions in both the test and control plots. Annual soil sampling and soil quality measurements are made within a ten-meter radius of these points. All offline data from ACA sites on soil properties (cation exchange capacity, $\mathrm{pH}$, organic matter), nutrients ( $\mathrm{P}, \mathrm{K}, \mathrm{S}, \mathrm{Ca}, \mathrm{Mg}, \mathrm{Cu}, \mathrm{Zn}, \mathrm{B}, \mathrm{Mn}, \mathrm{Fe}, \mathrm{Al}, \mathrm{P}$-saturation), soil physical quality (soil structure, bulk density, porosity, water holding capacity, infiltration rate) and biological properties (earthworm counts, above ground biomass, percentage plant cover) are presented in Zenodo data repository with annual updates (Mattila, 2020; Mattila and Heinonen, 2021). The offline field measurements at the intensive site Qvidja are described in Heimsch et al. (2021). Such offline, non-automated and infrequent data are currently being curated further for harmonization and reporting in JavaScript Object Notation (JSON) file formats and International Consortium for Agricultural Systems Applications (ICASA) standards (White et al., 2013). An example soil carbon measurement data point $\left(16.59 \pm 2.25 \mathrm{~kg} \mathrm{~m}^{-2}\right.$, average \pm standard deviation) is visualized on Qvidja graphs and available on the accompanying JSON file (https://data.lit.fmi.fi/field-observatory/qvidja/ec/events.json). 


\subsubsection{Field activity}

All field activity information (e.g. planting, fertilization, harvest timing and amount) is currently received offline through personal communication. An online application is under development for i) harmonizing historical field data, and for ii) collecting future field activity data. Accordingly, the application is being developed to allow the farmers themselves to enter these events and related details, and it will be tested for the first time at the end of the 2021 season. The application is written using the Shiny R package (v1.6.0, Chang et al., 2021) and it automatically produces files in a JSON format using the ICASA standards when possible (https://github.com/Ottis1/fo_management_data_input). Examples of historical field activity events (e.g. planting and tillage) that are prepared through this application are being made available in the Field Observatory JSON files and visualized on the graphs (Fig. 5).

\subsection{Online soil measurements}

Since 2020, each ACA site was provided with four TEROS-12 soil sensors (METER Group, Inc. USA) (two sensors per field, control and treatment) measuring volumetric water content, electrical conductivity and temperature (Table 3 ). The automated sensors are located at $75 \mathrm{~mm}$ depth in two of the three fixed measurement points of each field. The sensors were connected to a third party data transfer hardware (Datasense Oy, Finland), which uses Lora/WAN network to transmit the data. During the first year, the sensors measured every half hour but in 2021 measurement frequency was changed to one hour. The data is stored at the service providers server and is pulled to the PEcAn server (\#8) through the Datasense API. Currently the sensor array includes 80 TEROS-12 soil sensors, four $\mathrm{O}_{2}$ sensors (Apogee Instruments, USA) and two $\mathrm{CO}_{2}$ sensors (Vaisala Oy, Finland) and will be supplemented with weather and groundwater depth measurements.

\subsection{Online eddy covariance tower measurements}

Carbon dioxide, evapotranspiration (latent heat), sensible heat and momentum fluxes between the ecosystem and atmosphere are measured at the intensive study sites, Ruukki and Qvidja, using the micrometeorological eddy covariance (EC) technique. The EC instrumentation at both sites includes a three-axis sonic anemometer (uSonic-2 Scientific, METEK GmbH, Elmshorn, Germany) and an enclosed-path infrared gas analyser (LI-7200, LI-COR Biosciences, NE, USA) installed on a tower. The measurement height is $2.3 \mathrm{~m}$ in Qvidja and $3.3 \mathrm{~m}$ in Ruukki (2.3 m from 13 June to 25 June 2019 and $3.1 \mathrm{~m}$ from 25 June to 4 November 2019). For details of the measurement set-up in Qvidja, see Heimsch et al. (2021).

The data from the EC instruments are recorded at a $10-\mathrm{Hz}$ frequency. Half-hourly turbulent fluxes are calculated by blockaveraging these raw data after applying a double rotation of the coordinate system (McMillen, 1988). The time lag between the sonic anemometer and gas analyzer signals is determined based on the cross-correlation analysis (Rebmann et al., 2012). The gas fluxes are calculated from the mixing ratios determined with respect to dry air (Webb et al., 1980). The measured fluxes are compensated for the losses due to high-frequency signal attenuation within the measurement system (Laurila et al., 2005). The flux data are filtered for instrument malfunction and unfavourable flow conditions according to the following 
validity criteria: number of spikes in the raw data $<100$, mean $\mathrm{CO}_{2}$ mixing ratio $>350 \mathrm{ppm}$, relative stationarity (Foken and Wichura, 1996) $<30 \%$ and $\mathrm{CO}_{2}$ mixing ratio variance $<15 \mathrm{ppm}^{2}$ from April to September and $<5 \mathrm{ppm}^{2}$ from October to March. At the Ruukki site, flux data are accepted from the wind direction sector $135^{\circ}-315^{\circ}$ (Blocks 5, 6, 5up and 6up) and the sectors $0^{\circ}-90^{\circ}$ and $330^{\circ}-360^{\circ}$ (Blocks 1-4). In Qvidja, the wind directions representing the direction of the experimental site are $0^{\circ}-30^{\circ}$ and $140^{\circ}-360^{\circ}$. Periods of weak turbulence are filtered by applying a friction velocity threshold. The threshold and its uncertainty are estimated for each site-year using the moving-point-transition method (Reichstein et al., 2005) and a bootstrapping approach (Pastorello et al., 2020). For incomplete years, the estimates from the previous year are used.

The EC measurements are complemented with supporting meteorological observations conducted next to the flux tower. These include soil moisture, soil temperature at different depths, soil heat flux, photosynthetically active radiation (PAR), global and reflected solar radiation, air temperature and precipitation. Half-hourly meteorological and flux data are transmitted to a server at the FMI, which is then synchronized to the PEcAn server (\#8).

\subsubsection{Flux data processing}

The missing $\mathrm{CO}_{2}$ flux (net ecosystem exchange, NEE) data are gap-filled based on empirical response functions that are fitted separately for the gross primary production (GPP) and total ecosystem respiration (ER):

$N E E=G P P+E R$

Respiration is modelled as a function of air temperature:

$E R=R_{0} \cdot e^{E_{0} \cdot\left(\frac{1}{T_{0}}-\frac{1}{T_{a}-T_{1}}\right)}$

where $R_{0}$ is the respiration rate at the reference temperature of $283.15 \mathrm{~K}, \mathrm{~T}_{0}=227.13 \mathrm{~K}, \mathrm{~T}_{1}=56.02 \mathrm{~K}, \mathrm{E}_{0}$ is the temperature sensitivity of respiration, and $T_{a}$ is the measured air temperature (Lloyd and Taylor, 1994).

GPP is modelled as a function of PAR:

$$
G P P=\frac{\alpha \cdot P A R \cdot G P_{\max }}{\alpha \cdot P A R+G P_{\max }}
$$

where $\alpha$ is the apparent quantum yield and $\mathrm{GP}_{\max }$ is the asymptotic photosynthesis rate in optimal light conditions.

For gap-filling, the data are divided into blocks based on the harvest dates, and each block is gap-filled separately. First, R0 and $\mathrm{E}_{0}$ are estimated from the night-time (PAR $<20 \mu \mathrm{mol} \mathrm{m}^{-2} \mathrm{~s}^{-1}$ ) flux data with a 15-day moving window. If there are less than 25 observations, the window size is increased stepwise by two days until enough data are obtained. Similarly, $\alpha$ and GP $\max$ are determined with a three-day moving window by fitting the PAR response function to the daytime NEE from which the 
modelled respiration is subtracted. Gap-filled values that are determined using fits from asymmetrical time windows, with possibly biased data are flagged and updated when new measurements become available. Before flux gap-filling, the missing air temperature and PAR data are imputed using linear interpolation if the gap is not longer than $6 \mathrm{~h}$. Longer gaps are filled using the mean diel cycle of the data measured within seven days before or after the missing data point

The uncertainty of measured NEE ( $\mathrm{E}_{\text {meas }}$ ) is inferred from the model residuals. For each site-year, the measurements are grouped into $0.2 \mathrm{mg} \mathrm{CO}_{2} \mathrm{~m}^{-2} \mathrm{~s}^{-1}$ wide bins, and for each bin the measurement uncertainty is characterized as the standard deviation of the residuals. The uncertainty of each measured half-hourly flux is then estimated from the relation between the measurement uncertainty and the magnitude of the flux (Richardson et al., 2008). For incomplete years, the relation from the previous year is used.

The uncertainty of modelled NEE ( $\left.E_{\bmod }\right)$ is propagated from the uncertainties of the least-squares fits of modelled GPP (EGP) and Reco (EReco) as:

Finally, the uncertainty related to the friction velocity threshold $\left(\mathrm{E}_{\mathrm{ustar}}\right)$ is estimated by filtering the flux data using the 100 different bootstrapped friction velocity thresholds, gap-filling the 100 differently filtered datasets, and using the standard deviation of the gap-filled fluxes as an estimate for Eustar.

\subsection{FMI open weather data}

For all ACA sites, the weather information, namely precipitation, air temperature, relative humidity, wind speed and wind direction are retrieved from the nearest FMI weather stations (Table 2). Weather data are pulled to the PEcAn server using the fmir R package (https://github.com/mikmart/fmir).

\subsection{Satellite data from Google Earth Engine (GEE)}

All sites are monitored using remote sensing imagery from European Space Agency's (ESA) Sentinel-2 satellites. Atmospherically corrected Level-2A (L2A) Sentinel-2 multispectral data are retrieved using GEE (earthengine.google.com) cloud data platform. The scene classification band available in L2A products is used to filter away image acquisition dates during which the field is covered by snow, cloud or cloud shadow. Normalized Difference Vegetation Index (NDVI) is calculated using near infra-red (B8A) and red (B4) bands of the L2A products. The Leaf Area Index (LAI) is estimated using the ESA Sentinel Application Platform (SNAP) Biophysical Processor neural network algorithm (Weiss \& Baret, 2016, https://github.com/ollinevalainen/satellitetools). The NDVI data is natively available in $10 \mathrm{~m}$ resolution, whereas LAI is resampled to $10 \mathrm{~m}$ resolution from its original $20 \mathrm{~m}$ resolution. The satellite data is updated every two days at most (which is 
trapezoidal rule for all sites ("NDVI days"). Common starting and ending points for the active growing season, 31 March and 31 October, respectively, are used to standardize the cumulative NDVI sums between sites. To improve within site comparison, the cumulative NDVI is computed using dates when all fields within a site have satellite imagery available. The NDVI and LAI data is provided to the Field Observatory user interface in both raster (GeoTIFF) and tabular form (CSV).

With the tabular data, the average value of pixels within the field is used to estimate the field-level value. The tabular data is provided with $90 \%$ confidence intervals by multiplying the associated uncertainties by 1.645 . Non-realistic negative LAI values are capped to zero. For NDVI the uncertainty is presented as standard error of the mean (SE) of the pixels within the field. For the cumulative NDVI sum, the uncertainties are propagated using the Python uncertainties package (https://pythonhosted.org/uncertainties/) which automatically computes the required derivatives and propagates the uncertainties .

The uncertainty for the LAI $\left(u_{L A I}\right)$ is estimated by combining observational uncertainty $\left(S E_{L A I}\right)$ and the algorithmic uncertainty $\left(u_{\text {alg }}\right)$ of the LAI estimation:

$u_{L A I}=\sqrt{S E_{L A I}^{2}+u_{a l g}^{2}}$,

where the $S E_{L A I}$ is computed as the SE of LAI observations within the field. The $u_{\text {alg }}$ is calculated by propagating individual pixel uncertainties $\left(u_{t_{i}}\right)$ to the calculated average:

$u_{a l g}=n^{-1} \sqrt{\sum_{i=1}^{n} u_{t_{i}}^{2}}$,

where $\mathrm{n}$ is the number of pixels (i.e. sample size) and $u_{t}$ the reported theoretical RMSE for the SNAP LAI algorithm that is 0.89 (Weiss and Baret, 2016) and constant to all pixels. The artificial increase of $\mathrm{n}$ due to resampling LAI observations from its native $20 \mathrm{~m}$ resolution to $10 \mathrm{~m}$ is taken into account and $\mathrm{n}$ is reduced accordingly.

\subsection{PAR from Copernicus Atmospheric Monitoring Service (CAMS)}

For the ACA sites, the daily PAR data are derived from the global irradiation data obtained from the CAMS through daily queries (www.soda-pro.com/web-services/radiation/cams-radiation-service/, Qu et al., 2017). The global daily irradiation (Wh $\mathrm{m}^{-2}$ day $\left.^{-1}\right)$ is converted to daily PAR $\left(\mathrm{MJ} \mathrm{m}^{-2}\right.$ day $\left.^{-1}\right)$ assuming that $50 \%$ of the global irradiation is at PAR range. The CAMS data is available for each day with a $48 \mathrm{~h}$ time lag. The daily PAR is reported in $\mathrm{MJ} \mathrm{m}^{-2}$ day $^{-1}$ which is a more convenient unit for a daily value compared to $\mu \mathrm{mol} \mathrm{m} \mathrm{m}^{-2} \mathrm{~s}^{-1}$ used with 30-min measurement frequency in intensive sites. 
Geoscientific Instrumentation Methods and

Data Systems

Discussions

\subsection{ECMWF 15-day ensemble weather forecasts}

European Center Medium-range Weather Forecast (ECMWF) data are processed by the Finnish Meteorological Institute for every site. This dataset consists of 6-hourly 2 meter temperature ( $2 t$ variable in ECMWF standards), total precipitation $(t p)$, relative humidity $(r), 10$ meter $\mathrm{U}$ and $\mathrm{V}$ wind components ( $10 u$ and $10 v$, respectively), surface pressure ( $s p$ ), surface solar and thermal radiation downwards (ssrd and strd, respectively) values of 51 ensemble members where one member is the control forecast and the other 50 are perturbed members which have perturbed initial conditions different than the control to explore the range of uncertainty (Buizza and Richardson, 2017). Weather forecast data are updated everyday. Per ECMWF license agreements, the data are visualized as is but the disseminated tabular files are obfuscated.

Table 3 Summary of data streams reported in FiON. Offline $=$ stored in public data repository and updated as necessary.

\begin{tabular}{|c|c|c|c|c|c|c|}
\hline Data type & Units & Data source & Frequency & Since & Sites & $\begin{array}{l}\text { Online/offli } \\
\text { ne }\end{array}$ \\
\hline Field activity & - & $\begin{array}{c}\text { Personal } \\
\text { communication* }\end{array}$ & Seasonal & 2019 & All & Offline \\
\hline $\begin{array}{c}\text { Farmer } \\
\text { management } \\
\text { actions }\end{array}$ & - & Questionnaire & Annual & & All & Offline \\
\hline Soil C & $\begin{array}{c}\%(A C A) \\
k^{2} m^{-2} \\
\text { (Qvidja) }\end{array}$ & Lab measurements & Biannual & 2018 & $\begin{array}{c}\text { All, } \\
\text { except } \\
\text { Ruukki }\end{array}$ & Offline \\
\hline $\begin{array}{c}\text { Soil water } \\
\text { holding capacity }\end{array}$ & $m^{3} m^{-3}$ & Lab measurements & $\begin{array}{l}\text { Once to } \\
\text { calibrate } \\
\text { sensors }\end{array}$ & 2019 & $\begin{array}{c}\text { All, } \\
\text { except } \\
\text { Ruukki }\end{array}$ & Offline \\
\hline Soil nutrients & $\mathrm{mg} \mathrm{kg}^{-1}$ & Lab measurements & Biannual & 2018 & ACA & Offline \\
\hline Bulk density & $\mathrm{kg} \mathrm{dm}^{-3}$ & Lab measurements & Annual & 2019 & ACA & Offline \\
\hline Biomass & $\mathrm{kg} \mathrm{ha}^{-1}$ & Lab measurements & Annual & 2019 & ACA & Offline \\
\hline Soil moisture & $m^{3} m^{-3}$ & $\begin{array}{l}\text { ACA soil sensors \& } \\
\text { eddy covariance }\end{array}$ & $\begin{array}{l}\text { Half- } \\
\text { hourly }\end{array}$ & $\begin{array}{c}2018 \text { (Qvidja), } \\
2019 \text { (Ruukki), } \\
2020 \text { (ACA) }\end{array}$ & $\begin{array}{c}\text { ACA \& } \\
\text { Intensiv } \\
e\end{array}$ & Online \\
\hline Soil temperature & ${ }^{\circ} \mathrm{C}$ & $\begin{array}{l}\text { ACA soil sensors \& } \\
\text { eddy covariance }\end{array}$ & $\begin{array}{l}\text { Half- } \\
\text { hourly }\end{array}$ & $\begin{array}{c}2018 \text { (Qvidja), } \\
2019 \text { (Ruukki), } \\
2020 \text { (ACA) }\end{array}$ & $\begin{array}{c}\text { ACA \& } \\
\text { Intensiv } \\
\mathrm{e}\end{array}$ & Online \\
\hline $\begin{array}{c}\text { Electrical } \\
\text { conductivity }\end{array}$ & $\mu \mathrm{S} \mathrm{cm}-1$ & ACA soil sensors & $\begin{array}{l}\text { Half- } \\
\text { hourly }\end{array}$ & 2020 & ACA & Online \\
\hline $\mathrm{CO}_{2}$-flux & $\mathrm{mg} \mathrm{m}^{-2} \mathrm{~s}^{-}$ & Eddy covariance & Half- & 2018 (Qvidja), & Intensiv & Online \\
\hline
\end{tabular}


hourly 2019 (Ruukki) e

\begin{tabular}{|c|c|c|c|c|c|}
\hline $\begin{array}{l}\text { Latent and } \\
\text { sensible heat } \\
\text { flux }\end{array}$ & $\mathrm{W} \mathrm{m}^{-2}$ & Eddy covariance & $\begin{array}{l}\text { Half- } \\
\text { hourly }\end{array}$ & $\begin{array}{l}2018 \text { (Qvidja), } \\
2019 \text { (Ruukki) }\end{array}$ & $\begin{array}{c}\text { Intensiv } \\
\mathrm{e}\end{array}$ \\
\hline $\begin{array}{l}\text { Short-wave } \\
\text { radiation } \\
\text { (incoming and }\end{array}$ & $\mathrm{W} \mathrm{m} \mathrm{m}^{-2}$ & Eddy covariance & $\begin{array}{l}\text { Half- } \\
\text { hourly }\end{array}$ & $\begin{array}{l}2018 \text { (Qvidja), } \\
2019 \text { (Ruukki) }\end{array}$ & $\begin{array}{c}\text { Intensiv } \\
\mathrm{e}\end{array}$ \\
\hline
\end{tabular}
reflected)

\begin{tabular}{|c|c|c|c|c|c|c|}
\hline $\begin{array}{c}\mathrm{CO}_{2} \\
\text { concentration }\end{array}$ & ppm & Eddy covariance & $\begin{array}{l}\text { Half- } \\
\text { hourly }\end{array}$ & $\begin{array}{l}2018 \text { (Qvidja), } \\
2019 \text { (Ruukki) }\end{array}$ & $\begin{array}{c}\text { Intensiv } \\
\mathrm{e}\end{array}$ & Online \\
\hline Precipitation & $\mathrm{mm}$ & $\begin{array}{l}\text { FMI open weather \& } \\
\text { eddy covariance }\end{array}$ & $\begin{array}{l}\text { Half- } \\
\text { hourly }\end{array}$ & $\begin{array}{c}2018 \text { (Qvidja), } \\
2019 \text { (ACA \& } \\
\text { Ruukki) }\end{array}$ & $\begin{array}{c}\text { ACA \& } \\
\text { Intensiv } \\
\mathrm{e}\end{array}$ & Online \\
\hline Air Temperature & ${ }^{\circ} \mathrm{C}$ & $\begin{array}{l}\text { FMI open weather \& } \\
\text { eddy covariance }\end{array}$ & $\begin{array}{l}\text { Half- } \\
\text { hourly }\end{array}$ & $\begin{array}{c}2018 \text { (Qvidja), } \\
2019 \text { (ACA \& } \\
\text { Ruukki) }\end{array}$ & $\begin{array}{c}\text { ACA \& } \\
\text { Intensiv } \\
\mathrm{e}\end{array}$ & Online \\
\hline $\begin{array}{l}\text { Relative } \\
\text { Humidity }\end{array}$ & $\%$ & $\begin{array}{l}\text { FMI open weather \& } \\
\text { eddy covariance }\end{array}$ & $\begin{array}{l}\text { Half- } \\
\text { hourly }\end{array}$ & $\begin{array}{c}2018 \text { (Qvidja), } \\
2019 \text { (ACA \& } \\
\text { Ruukki) }\end{array}$ & $\begin{array}{c}\text { ACA \& } \\
\text { Intensiv } \\
\mathrm{e}\end{array}$ & Online \\
\hline PAR & 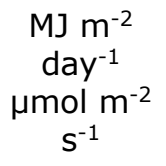 & $\begin{array}{c}\text { Copernicus \& eddy } \\
\text { covariance }\end{array}$ & $\begin{array}{l}\text { Daily \& } \\
\text { half- } \\
\text { hourly }\end{array}$ & $\begin{array}{c}2018 \text { (Qvidja), } \\
2019 \text { (ACA \& } \\
\text { Ruukki) }\end{array}$ & $\begin{array}{c}\text { ACA \& } \\
\text { Intensiv } \\
\text { e }\end{array}$ & Online \\
\hline Leaf Area Index & $\mathrm{m}^{2} \mathrm{~m}^{-2}$ & Sentinel-2, GEE & $\begin{array}{l}\text { Min 2- } \\
\text { days }\end{array}$ & $\begin{array}{c}2018 \text { (Qvidja), } \\
2019 \text { (ACA \& } \\
\text { Ruukki) }\end{array}$ & All & Online \\
\hline NDVI & - & Sentinel-2, GEE & $\begin{array}{l}\text { Min 2- } \\
\text { days }\end{array}$ & $\begin{array}{c}2018 \text { (Qvidja), } \\
2019 \text { (ACA \& } \\
\text { Ruukki) }\end{array}$ & All & Online \\
\hline
\end{tabular}

*Online application is under development.

\subsection{Predictive Ecosystem Analyzer (PEcAn) server}

All FiON data are pooled in an FMI server where model-data integration cyberinfrastructure software PEcAn is installed and compiled. PEcAn is an ecological informatics toolbox that consists of process-based models, a workflow management system and analytical tools for model-data synthesis (LeBauer et al., 2013; Dietze et al., 2013). The automated PEcAn workflow calls a series of modularized tasks that involve pre-processing of the model inputs, configuring and running the models, post- 
requires writing a model package which consists of a few interfacing scripts as PEcAn adopts intermediate input and output file formats, and applies pre- and post-model run analyses to these standards (Fer et al., 2021). While there are already many ecosystem models coupled to PEcAn and its design is general across process-based models, coupling of more models that can simulate agricultural ecosystems is in progress. In this study, we coupled the BASGRA_N model (Basic Grassland Model, Höglind et al., 2020) to the PEcAn workflow and demonstrated its use for the Qvidja site (see Sect. 4, Model-data synthesis). In the future, we will provide model predictions for all sites through PEcAn.

\subsection{Public data storage}

To harmonize the data, all tabular data with less than daily measurement frequency is aggregated to a 30 min interval (to every hour and half hour) before transferring the data to the public data storage (Amazon Simple Storage Service, fieldobservatory.data.lit.fmi.fi). To protect the privacy of the farmers, all data holding spatial information is transformed for all ACA sites, except for site MU (which is operated by Häme University of Applied Sciences).

\subsection{Field Observatory user interface}

61 The Field Observatory user interface (v1.0, fieldobservatory.org) allows viewing general information about the sites and the measurements and carbon farming practices conducted on them. The website has an interactive map to navigate to site-specific dashboards. A site view consists of general information about the site, an interactive map with satellite imagery of a specified vegetation parameter, an interactive timeline for selecting satellite imagery for viewing, and a panel of interactive time series charts (Fig. 3). Each chart comes with a description of the displayed data. A chart typically contains multiple time series and the visibility of each can be toggled. The user can enable and disable time aggregation and choose the time aggregation level from predefined options. The time aggregation is calculated using sliding statistics such as mean or sum depending on the data type. Any chart can be exported as an SVG image or as a CSV file containing the displayed data. A global specification file defines a list of charts and the data source types that can be shown in each chart. Site-specific specification files are used to define data source types available for each site and to provide links to the data files. Specification files are stored in JSON format. browser. Maps have been implemented using Mapbox GL JS JavaScript library. 
https://doi.org/10.5194/gi-2021-21

Preprint. Discussion started: 2 August 2021

(c) Author(s) 2021. CC BY 4.0 License.

\section{(c) (i)}

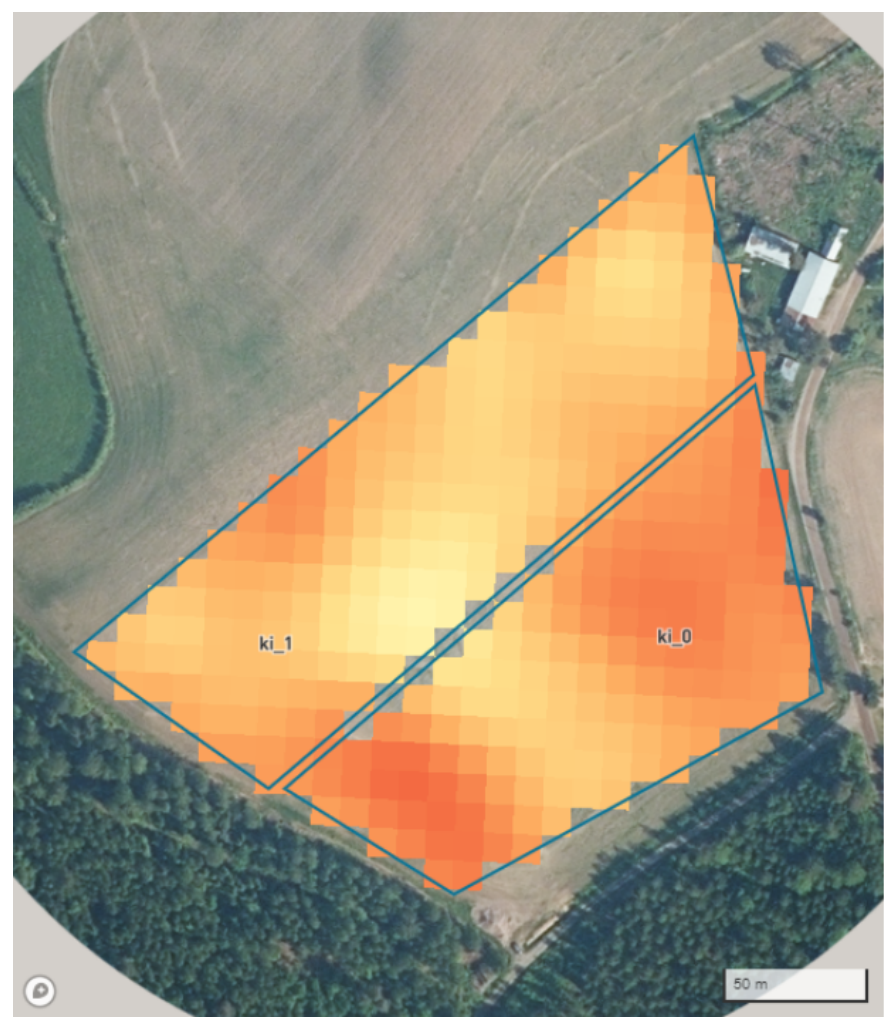

.75

(a)

\section{KI}

Advanced CarbonAction Site

$\mathrm{KI}$ field is a low OM sand in organic crop rotation. The aim is to increase OM by adding organic matter through soil amendments (wood pulp, ramial woodchips).

\section{FARMING METHODS}

Management: soil amendments

Species: multi-species ley

Soil type: fine sand

\section{SATELLITE IMAGES}

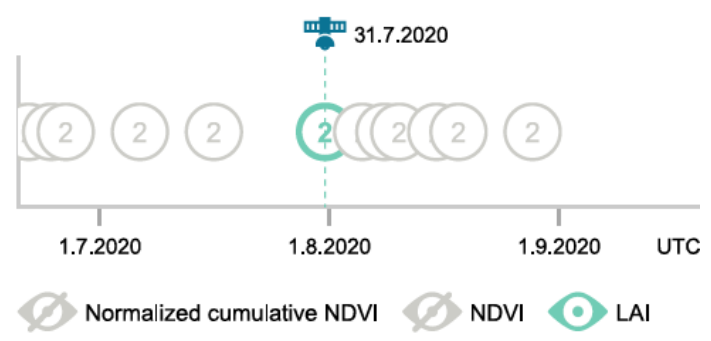




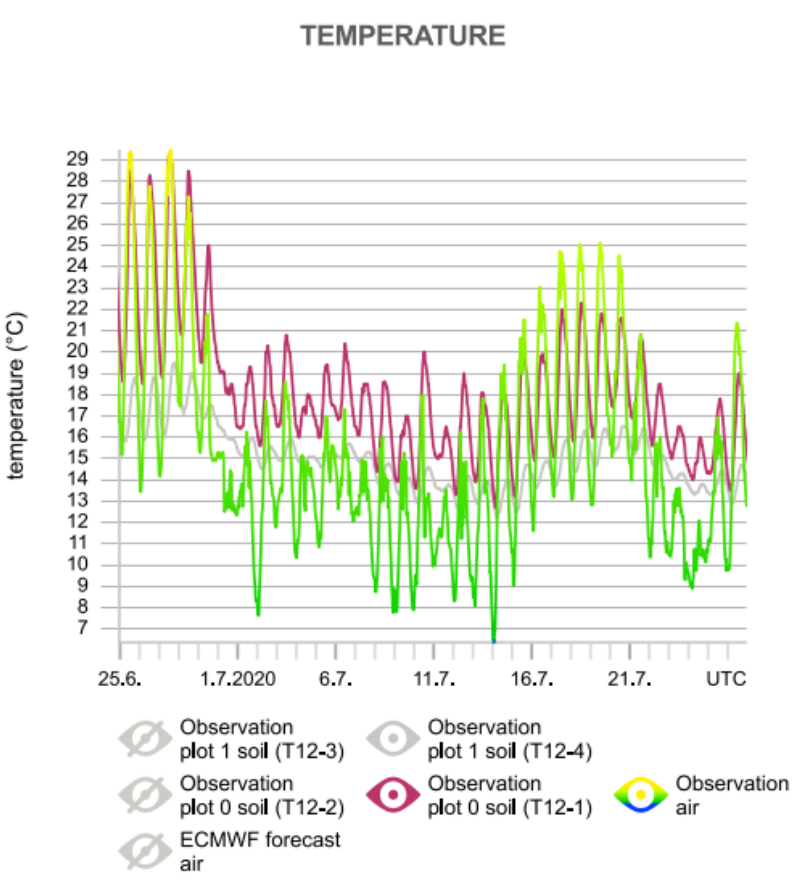

Soil temperature controls plant and microbe activity. Increase of 10 $\mathrm{deg} \mathrm{C}$ roughly doubles growth and decomposition. Air temperature controls soil temperature in the long term.

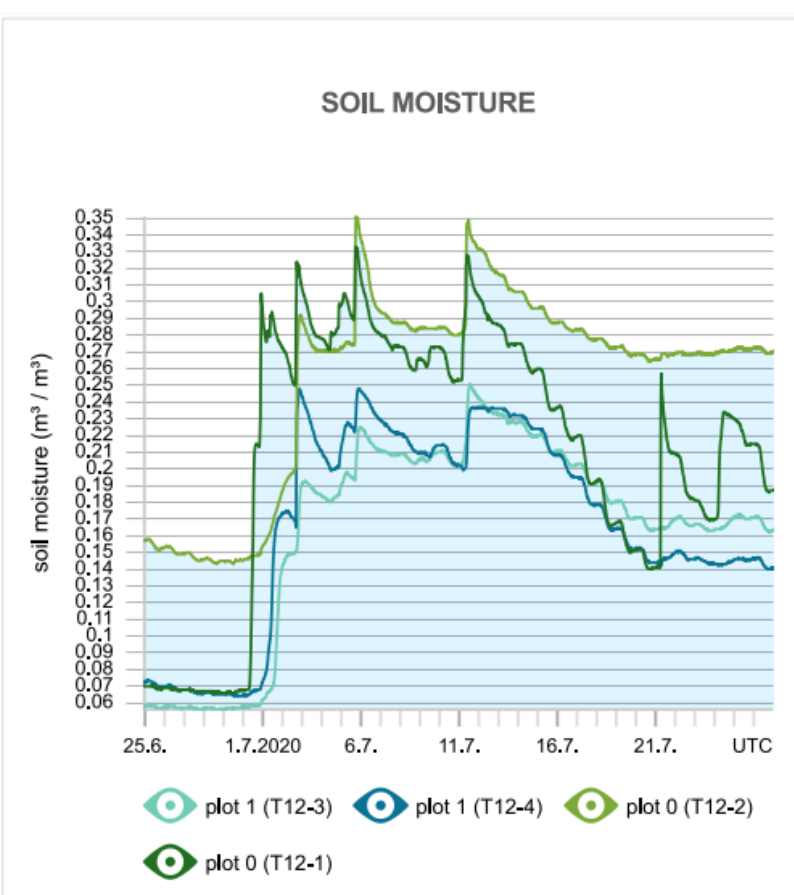

Soil moisture is a key driver for plant an microbe activity. In addition it tracks the water budget of the soil. $0.5 \mathrm{~m} 3$ water $/ \mathrm{m}^{3}$ soil $=100 \mathrm{~mm}$ water in $20 \mathrm{~cm}$ depth of soil.

Figure 3 Two web interface views of the measurement data for site KI: (a) Overview and LAI satellite images and (b) observed soil and air temperature and soil moisture. The reader is referred to the website www.fieldobservatory.org for more and interactive charts. The aerial photo contains data from the National Land Survey of Finland Topographic Database (11/2020).

4 Model-data synthesis and decision support

While the current version of the Field Observatory mainly disseminates observations, one of the main goals of this application is to provide accessible near real-time model-data synthesis, forecasting and decision support for the users. We demonstrate the first application of this service at the Qvidja grassland site with the grassland model BASGRA_N (Table 2). BASGRA_N model is developed specifically for northern climates and for grass types (timothy, Phleum pratense; meadow fescue, Festuca pratensis) that are the dominating forage species cultivated at the Qvidja farm, and it is able to simulate grassland productivity, quality and greenhouse gas balance (Höglind et al., 2020). 
We coupled BASGRA_N to PEcAn, and used PEcAn's workflow management system and analytical tools (specifically the Bayesian calibration and state data assimilation modules) to inform the model with the data. Before employing them for forecasting and decision support, these models need to be initialized and calibrated. Therefore, we used the field and lab measurements (Sect. 3.1), such as the rooting depth, soil carbon content and soil water holding capacity, to initialize the model states. Next, using multiple constraints $\left(\mathrm{CO}_{2}\right.$ flux and LAI from the eddy covariance tower field, Sect. 3.3), we calibrated 20 model parameters using Bayesian numerical methods through the BayesianTools R-package (Hartig et al., 2019) as implemented in the PEcAn system (Fer et al., 2018). In calibration, we used the observations from May 2018 to April 2021. After calibration model predictions were improved in terms of both uncertainty reduction and accuracy (Fig. 4).

$\mathrm{CO}_{2}$ flux $\left(\mathrm{mg} / \mathrm{m}^{2} / \mathrm{s}\right)$

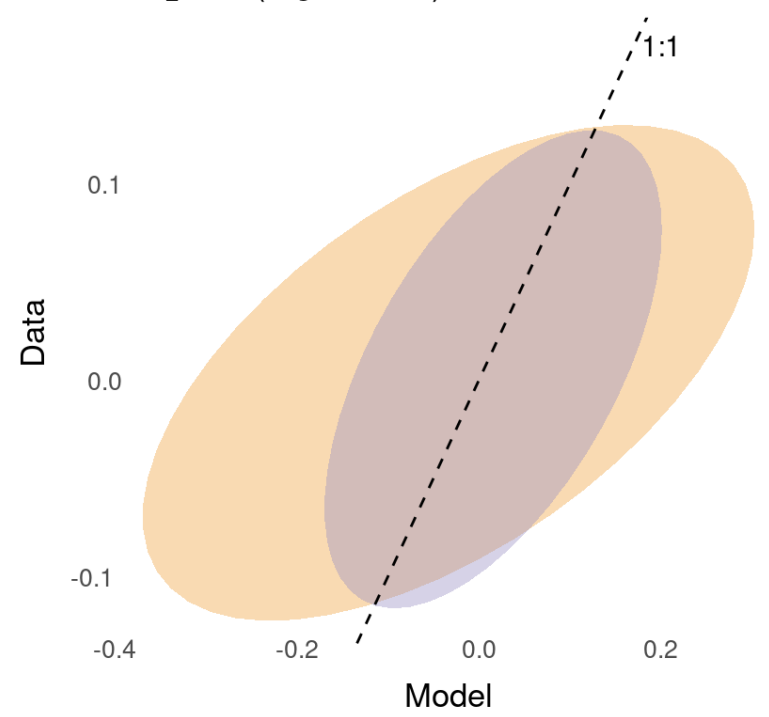

$\operatorname{LAI}\left(\mathrm{m}^{2} / \mathrm{m}^{2}\right)$

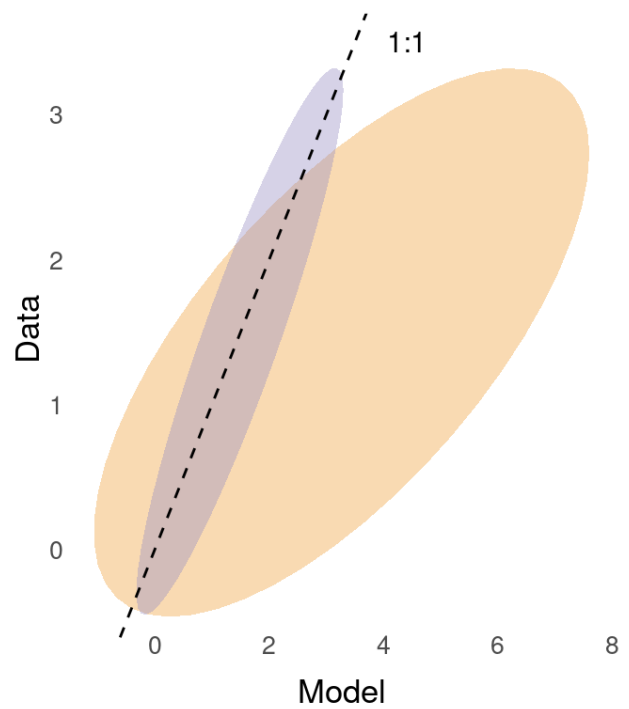

pre-calibration post-calibration

Figure 4 Predicted versus observed comparison before (orange ellipses) and after (purple ellipses) initialization and calibration. Ellipses represent the $90 \%$ CI of model ensemble runs with 500 members. After initialization and calibration, the model performance at Qvidja improved in terms of both accuracy (closer to the 1:1 line) and uncertainty reduction (narrower ellipses).

Next, we deployed the initialized and calibrated model in an online, operational, iterative near-term forecasting framework by driving it with the ECMWF ensemble 15-day weather forecast (Sect. 3.7). From April 2021 onwards, every day a 15-day ensemble forecast is made from the BASGRA_N model. As time progresses, each day the $\mathrm{CO}_{2}$ flux forecast is informed with the observed and gap-filled daily $\mathrm{CO}_{2}$ flux values within an iterative forecast-analysis cycle using the Extended Ensemble Kalman filter algorithm implemented in PEcAn (Dietze, 2017). When LAI observations are also available, they are jointly assimilated with the $\mathrm{CO}_{2}$ flux measurements as well. Although we are currently only assimilating the $\mathrm{CO}_{2}$ flux and LAI observations, related states are also updated within the model through the analysis step as the model encodes and simulates 
13 relations and covariances among different ecosystem processes. Among the model output variables, we share the $\mathrm{LAI}_{\text {and }} \mathrm{CO}_{2}$

14 flux (Fig. 5), as well as Latent Heat and Yield Potential forecasts with the users through the Field Observatory user interface, 15 albeit only for the Qvidja site for the time being.
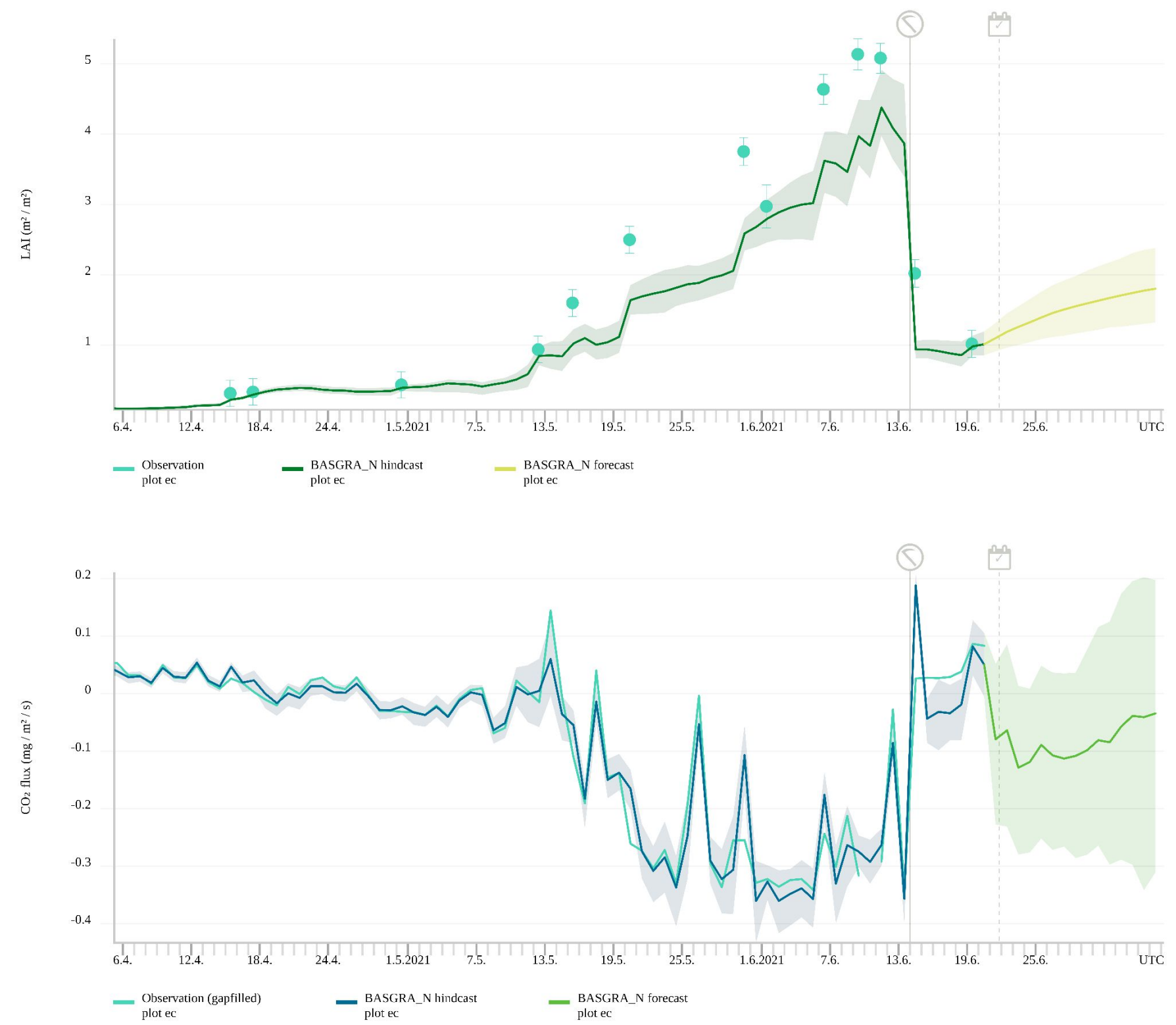

17 Figure 5 15-day LAI (top) and $\mathrm{CO}_{2}$ flux (bottom) forecast at Qvidja. The $90 \%$ confidence intervals for hindcast and forecast are generated by 250 ensemble members, with different combinations of model parameters, initial conditions and meteorological drivers. Units in the $\mathrm{CO}_{2}$ flux graph are given per second to reflect the measurement frequency, however, 
observations were aggregated to daily time step here to align with the model predictions. The scythe icon indicates a harvest event on June 14th, 2021.

\section{Discussion}

This paper introduced the Field Observatory Network (FiON) and its unified methodology leading the way to monitor and forecast the functioning of agricultural ecosystems, geared towards verification of soil carbon sequestration. This methodology combines the existing spatially scattered measurements, modeling and computing networks, and disseminates the model-data computation outcomes through the Field Observatory user interface. In the following, we discuss the scientific and practical contributions of FiON and the Field Observatory, and the future steps planned for both.

\subsection{Scientific contribution}

FiON adopts state-of-the-art field and laboratory methods, open data sources, near real-time satellite imagery processing and model-data integration cyberinfrastructures - all of which are needed for a reliable MRV platform. A distinct feature of FiON is the network of ordinary farms, ACA sites, to establish baseline trends and verify additional changes. As soil carbon pool changes slowly, even after a shift in management practices, long-term monitoring is needed. The ACA sites (with control and treatment plots) were specifically designed for this purpose and will be monitored continuously for at least the next five years, and FiON aspires to continue even longer. This is an adequate time frame to detect SOC changes because the fastest carbon re-accumulation occurs in the first 10-20 years, depending on soil type, management practices, climate and initial SOC (Bossio et al., 2020), all of which are monitored by FiON. The intensive and ACA sites provide an important benchmarking opportunity to our model-data synthesis methodology which will be applied to all 100 Carbon Action farms. The PEcAn platform is central to our methodology; it enables synthesizing different data sources and process-based models, managing observational and model uncertainties, and near real-time forecasting. It distinguishes FiON from observations-only approaches.

\subsection{Practical contribution}

The Field Observatory user interface has not only enabled farmers to monitor impacts of their carbon farming practices, but also to connect and compare their own and others' data and practices. Features in the user interface are co-created with the farmers and developed accordingly. For example, farmers requested to see a cumulative sum of NDVI through the growing season which was in return calculated and included on the website. Likewise, simple and clear descriptions to interpret each data type have been found helpful. The gap-filled $\mathrm{CO}_{2}$ fluxes at the intensive study sites have made it easier to communicate carbon exchanges between land and the atmosphere and how carbon budget calculations are done. As a result, the Field the Carbon Action farmers. 
One of our aims with this framework is to provide decision support for the end users. Although such functionality is not fully in place yet (but planned for the future versions), establishing the operational data assimilation and iterative forecasting pipeline is a milestone towards this direction. Users are quantitatively informed about the progression of various ecosystem states and services by these Field Observatory near-term forecast updates. The current pipeline is further being developed to improve the model performance and to be put into an adaptive decision making framework where alternative scenarios will be simulated with the model to aid users in their day-to-day operations.

There is a large interest towards adopting and developing Field Observatory further. Therefore, the website is under constant development with new features, and new information about carbon farming and findings of FiON are increasingly being made available.

\subsection{Avenues for future research and development}

We have planned future steps for both FiON and the Field Observatory. The first step is to add more agricultural models to PEcAn. This enables us to extend model-data analysis to all FiON sites where different species and management practices are involved (i.e. other than grass harvest timing and amount). Coupling of one such additional model (Simulateur mulTIdisciplinaire pour les Cultures Standard, STICS, Brisson et al., 1998) to PEcAn has already been completed, and others are in progress. In the meantime, more sites will be added to FiON, not only in number but also in type. For example, with carbon-smart planning, urban vegetation also has potential to store more carbon. We study this also in FiON and consequently urban sites will be added. Another goal is to include forests and peatlands in FiON, which requires incorporating new processbased models in the FiON workflow. During the coming years, more field and laboratory measurement data will be collected and used to validate the model estimates and re-calibrate the models.

The development of the online application to gather field activity data from farmers is also in progress. This application will not only allow using field activity data in visualization and model-data synthesis but it will also enable the farmers to simulate a predefined number of scenarios regarding their day-to-day operations by triggering automated PEcAn workflows-for example, given the next 15-day forecast they will be able to optimize the timing and amounts of their field activity. In this context, Field Observatory's interoperability with commercial farm management information systems needs to be studied.

We are currently also investigating the use of satellite data sources other than Sentinel-2 in retrieving information on vegetation and soil properties. In addition to satellite imagery, drones could be used as a source of remote sensing data. Finally, the data streams used in data assimilation (to inform and update forecasts) will be increased and improvement in forecasting skills will be analyzed. 


\section{Conclusions}

The Field Observatory Network (FiON) introduced in this paper is primarily a network of researchers, farmers, companies and other stakeholders developing carbon farming practices. FiON provides a unified methodology to monitor and forecast agricultural carbon sequestration by combining offline and near real-time field measurements, weather data, satellite imagery, modeling and computing networks. FiON disseminates data through the Field Observatory user interface (www.fieldobservatory.org). For farmers, FiON serves as a monitoring and decision support tool. In contrast to the mainstream decision support tools, FiON also provides the farmers access to other carbon farmers' data in the network. This enables comparisons and knowledge transfer between the carbon farmers.

FiON has several analogies to other ecological observatory networks, but unlike these existing networks, FiON is designed to provide near real-time information and forecasts concerning the carbon farming practices and to facilitate monitoring and verification of carbon sequestration. In this sense, FiON takes several steps forward from the mainstream of the ecological observatory networks known so far.

\section{Data availability}

The data displayed in the Field Observatory are available from the Field Observatory website (www.fieldobservatory.org) and from Amazon Simple Storage Service at https://field-observatory.data.lit.fmi.fi/index.html. Field measurements conducted at ACA sites in 2019 and 2020 are available from Zenodo data repository (Mattila, 2020: Mattila and Heinonen, 2021).

\section{Code availability}

The satellite data processing codes are available from a public GitHub repository (https://github.com/ollinevalainen/satellitetools). All PEcAn code is available openly on a GitHub repository (https://github.com/PecanProject/pecan). Field Activity data collection and curation application code which is under development is also available via GitHub (https://github.com/Ottis1/fo_management_data input). Rest of the codes by the authors are not yet openly available.

\section{Author contribution}

Conceptualization, ON, ONi, IF, AJ, TM, OK, JK, LH, LM, PJ, LK, ÅS, AL, JHe, IK, JL; Data curation, ON, IF, ONi, TM, OKu; Formal Analysis, ON, IF, ONi, TM, LHe, HV, SG, TV, JV, JT, Funding acquisition, TM, LK, AL, TL, JHe, TA, IK, JL; Investigation, ON, IF, ONi, TM, LHe, HV, SG, TV, JV, JT; Methodology, ON, IF, ONi, TM, HV, LK, OKu, TV, JV, JT, JHe, 
TA, JL; Project administration, TM, JK, LH, LK, ÅS, AL, TL, JHe, TA, IK, JL; Software, ON, ONi, IF, AJ, OK, OKu, HV, TV, JV, JT; Visualization, ON, ONi, IF, AJ, LM, PJ, OKu and comments from all; Writing - original draft preparation, all authors; Writing - review \& editing, all authors.

\section{Competing interests}

14 The authors declare that they have no conflict of interest.

\section{Acknowledgments}

The work of HAMK has been conducted within the research project: Carbon 4.0 - Analysis and utilization of biological data in complex carbon ecosystems funded by the Ministry of Education and Culture (Finland). The work by FMI was supported by Business Finland [grant 6905/31/2018], The Strategic Research Council at the Academy of Finland [decision no 327214], the Academy of Finland Flagship Program [decision no 337552], the Ministry of Agriculture and Forestry of Finland [grant VN/5094/2021] and Maj and Tor Nessling foundation (grant 202000391). The work by SYKE was supported by The Strategic Research Council at the Academy of Finland [decision no 327350].

The authors want to thank the 20 farmers who allowed testing the framework on their Carbon Action fields. We also thank the owner of Ruukki farm, Natural Resources Institute Finland (Luke), and their employees for making it possible to have a measurement site there. In addition, we are thankful for the owners and staff of Qvidja farm.

\section{References}

Bellamy, P. H., Loveland, P. J., Bradley, R. I., Lark, R. M., and Kirk, G. J. D.: Carbon losses from all soils across England and Wales 1978-2003, Nature, 437, 245-248, https://doi.org/10.1038/nature04038, 2005.

Bossio, D. A., Cook-Patton, S. C., Ellis, P. W., Fargione, J., Sanderman, J., Smith, P., Wood, S., Zomer, R. J., von Unger, M., https://doi.org/10.1038/s41893-020-0491-z, 2020.

Buizza, R. and Richardson, D.: 25 years of ensemble forecasting at ECMWF, https://doi.org/10.21957/BV418O, 2017. 2019. 
Dietze, M.: Ecological Forecasting, Princeton University Press, https://doi.org/10.1515/9781400885459, 2017.

Elmendorf, S. C., Jones, K. D., Cook, B. I., Diez, J. M., Enquist, C. A. F., Hufft, R. A., Jones, M. O., Mazer, S. J., MillerRushing, A. J., Moore, D. J. P., Schwartz, M. D., and Weltzin, J. F.: The plant phenology monitoring design for The National Ecological Observatory Network, Ecosphere, 7, e01303, https://doi.org/10.1002/ecs2.1303, 2016.

Fer, I., Kelly, R., Moorcroft, P. R., Richardson, A. D., Cowdery, E. M., and Dietze, M. C.: Linking big models to big data: efficient ecosystem model calibration through Bayesian model emulation, Biogeosciences, 15, 5801-5830, https://doi.org/10.5194/bg-15-5801-2018, 2018.

Fer, I., Gardella, A. K., Shiklomanov, A. N., Campbell, E. E., Cowdery, E. M., De Kauwe, M. G., Desai, A., Duveneck, M. J., Fisher, J. B., Haynes, K. D., Hoffman, F. M., Johnston, M. R., Kooper, R., LeBauer, D. S., Mantooth, J., Parton, W. J., Poulter, B., Quaife, T., Raiho, A., Schaefer, K., Serbin, S. P., Simkins, J., Wilcox, K. R., Viskari, T., and Dietze, M. C.: Beyond ecosystem modeling: A roadmap to community cyberinfrastructure for ecological data-model integration, Glob. Change Biol., 27, 13-26, https://doi.org/10.1111/gcb.15409, 2021.

Foken, Th. and Wichura, B.: Tools for quality assessment of surface-based flux measurements, Agricultural and Forest Meteorology, 78, 83-105, https://doi.org/10.1016/0168-1923(95)02248-1, 1996.

Guerra, C. A., Bardgett, R. D., Caon, L., Crowther, T. W., Delgado-Baquerizo, M., Montanarella, L., Navarro, L. M., Orgiazzi, Cowan, D. A., Djukic, I., van den Hoogen, J., Lehmann, A., Maestre, F. T., Marín, C., Reitz, T., Rillig, M. C., Smith, L. C., de Vries, F. T., Weigelt, A., Wall, D. H., and Eisenhauer, N.: Tracking, targeting, and conserving soil biodiversity, Science, 371, 239-241, https://doi.org/10.1126/science.abd7926, 2021.

Heikkinen, J., Ketoja, E., Nuutinen, V., and Regina, K.: Declining trend of carbon in Finnish cropland soils in 1974-2009, Glob Change Biol, 19, 1456-1469, https://doi.org/10.1111/gcb.12137, 2013.

Heikkinen, J., Keskinen, R., Regina, K., Honkanen, H., and Nuutinen, V.: Estimation of carbon stocks in boreal cropland soils

Heimsch, L., Lohila, A., Tuovinen, J.-P., Vekuri, H., Heinonsalo, J., Nevalainen, O., Korkiakoski, M., Liski, J., Laurila, T., and Kulmala, L.: Carbon dioxide fluxes and carbon balance of an agricultural grassland in southern Finland, Biogeosciences, 18, 3467-3483, https://doi.org/10.5194/bg-18-3467-2021, 2021.

Hinckley, E. S., Bonan, G. B., Bowen, G. J., Colman, B. P., Duffy, P. A., Goodale, C. L., Houlton, B. Z., Marín-Spiotta, E., Ogle, K., Ollinger, S. V., Paul, E. A., Vitousek, P. M., Weathers, K. C., and Williams, D. G.: The soil and plant biogeochemistry sampling design for The National Ecological Observatory Network, Ecosphere, 7, https://doi.org/10.1002/ecs2.1234, 2016. 
Geoscientific Instrumentation Methods and Data Systems

Discussions

Hipsey, M. R., Bruce, L. C., Boon, C., Busch, B., Carey, C. C., Hamilton, D. P., Hanson, P. C., Read, J. S., de Sousa, E., Weber, M., and Winslow, L. A.: A General Lake Model (GLM 3.0) for linking with high-frequency sensor data from the Global Lake Ecological Observatory Network (GLEON), Geosci. Model Dev., 12, 473-523, https://doi.org/10.5194/gmd-12473-2019, 2019.

Höglind, M., Cameron, D., Persson, T., Huang, X., and van Oijen, M.: BASGRA_N: A model for grassland productivity, quality and greenhouse gas balance, Ecological Modelling, 417, 108925, https://doi.org/10.1016/j.ecolmodel.2019.108925, 2020.

Keller, M., Schimel, D. S., Hargrove, W. W., and Hoffman, F. M.: A continental strategy for the National Ecological Observatory Network, Frontiers in Ecology and the Environment, 6, 282-284, https://oi.org/10.1890/15409295(2008)6[282:ACSFTN]2.0.CO;2, 2008.

Köchy, M., Hiederer, R., and Freibauer, A.: Global distribution of soil organic carbon - Part 1: Masses and frequency distributions of SOC stocks for the tropics, permafrost regions, wetlands, and the world, SOIL, 1, 351-365, https://doi.org/10.5194/soil-1-351-2015, 2015.

Lal, R., Negassa, W., and Lorenz, K.: Carbon sequestration in soil, Current Opinion in Environmental Sustainability, 15, 7986, https://doi.org/10.1016/j.cosust.2015.09.002, 2015.

Laurila, T., Tuovinen, J.-P., Lohila, A., Hatakka, J., Aurela, M., Thum, T., Pihlatie, M., Rinne, J., and Vesala, T.: Measuring methane emissions from a landfill using a cost-effective micrometeorological method: MEASURING METHANE EMISSIONS, Geophys. Res. Lett., 32, n/a-n/a, https://doi.org/10.1029/2005GL023462, 2005.

Lloyd, J. and Taylor, J. A.: On the Temperature Dependence of Soil Respiration, Functional Ecology, 8, 315, https://doi.org/10.2307/2389824, 1994.

Mattila, T.: Carbon action MULTA Finnish carbon sequestration experimental field dataset 2019, https://doi.org/10.5281/ZENODO.3670654, 2020.

Mattila, T., Hagelberg, E., Söderlund, S., and Joona, J.: How farmers approach carbon sequestration? Lessons learned from 105 Carbon Farming Plans., Paper submitted to Soil and Tillage Research, 2021.

Mattila, Tuomas and Heinonen, Reija: Carbon action MULTA Finnish carbon sequestration experimental field dataset 2020, https://doi.org/10.5281/ZENODO.4068271, 2021.

McMillen, R. T.: An eddy correlation technique with extended applicability to non-simple terrain, Boundary-Layer Meteorol, 43, 231-245, https://doi.org/10.1007/BF00128405, 1988. 
Geoscientific Instrumentation Methods and Data Systems

Discussions

Meersmans, J., Van Wesemael, B., De Ridder, F., Fallas Dotti, M., De Baets, S., and Van Molle, M.: Changes in organic carbon distribution with depth in agricultural soils in northern Belgium, 1960-2006: CHANGES IN SOC OF NORTHERN BELGIUM, 15, 2739-2750, https://doi.org/10.1111/j.1365-2486.2009.01855.x, 2009.

Merante, P., Dibari, C., Ferrise, R., Sánchez, B., Iglesias, A., Lesschen, J. P., Kuikman, P., Yeluripati, J., Smith, P., and Bindi, M.: Adopting soil organic carbon management practices in soils of varying quality: Implications and perspectives in Europe, Soil and Tillage Research, 165, 95-106, https://doi.org/10.1016/j.still.2016.08.001, 2017.

Minasny, B., Malone, B. P., McBratney, A. B., Angers, D. A., Arrouays, D., Chambers, A., Chaplot, V., Chen, Z.-S., Cheng, K., Das, B. S., Field, D. J., Gimona, A., Hedley, C. B., Hong, S. Y., Mandal, B., Marchant, B. P., Martin, M., McConkey, B. G., Mulder, V. L., O’Rourke, S., Richer-de-Forges, A. C., Odeh, I., Padarian, J., Paustian, K., Pan, G., Poggio, L., Savin, I., Stolbovoy, V., Stockmann, U., Sulaeman, Y., Tsui, C.-C., Vågen, T.-G., van Wesemael, B., and Winowiecki, L.: Soil carbon 4 per mille, Geoderma, 292, 59-86, https://doi.org/10.1016/j.geoderma.2017.01.002, 2017.

Oldfield, E. E., Wood, S. A., and Bradford, M. A.: Direct effects of soil organic matter on productivity mirror those observed with organic amendments, Plant Soil, 423, 363-373, https://doi.org/10.1007/s11104-017-3513-5, 2018.

Pastorello, G., Trotta, C., Canfora, E., Chu, H., Christianson, D., Cheah, Y.-W., Poindexter, C., Chen, J., Elbashandy, A., Humphrey, M., Isaac, P., Polidori, D., Reichstein, M., Ribeca, A., van Ingen, C., Vuichard, N., Zhang, L., Amiro, B., Ammann, C., Arain, M. A., Ardö, J., Arkebauer, T., Arndt, S. K., Arriga, N., Aubinet, M., Aurela, M., Baldocchi, D., Barr, A., Beamesderfer, E., Marchesini, L. B., Bergeron, O., Beringer, J., Bernhofer, C., Berveiller, D., Billesbach, D., Black, T. A., Blanken, P. D., Bohrer, G., Boike, J., Bolstad, P. V., Bonal, D., Bonnefond, J.-M., Bowling, D. R., Bracho, R., Brodeur, J., Brümmer, C., Buchmann, N., Burban, B., Burns, S. P., Buysse, P., Cale, P., Cavagna, M., Cellier, P., Chen, S., Chini, I., Christensen, T. R., Cleverly, J., Collalti, A., Consalvo, C., Cook, B. D., Cook, D., Coursolle, C., Cremonese, E., Curtis, P. S., D’Andrea, E., da Rocha, H., Dai, X., Davis, K. J., Cinti, B. D., Grandcourt, A. de, Ligne, A. D., De Oliveira, R. C., Delpierre, N., Desai, A. R., Di Bella, C. M., Tommasi, P. di, Dolman, H., Domingo, F., Dong, G., Dore, S., Duce, P., Dufrêne, E., Dunn, A., Dušek, J., Eamus, D., Eichelmann, U., ElKhidir, H. A. M., Eugster, W., Ewenz, C. M., Ewers, B., Famulari, D., Fares, S., Feigenwinter, I., Feitz, A., Fensholt, R., Filippa, G., Fischer, M., Frank, J., Galvagno, M., et al.: The FLUXNET2015 dataset and the ONEFlux processing pipeline for eddy covariance data, Scientific Data, 7, 225, https://doi.org/10.1038/s41597-0200534-3, 2020.

Qu, Z., Oumbe, A., Blanc, P., Espinar, B., Gesell, G., Gschwind, B., Klüser, L., Lefèvre, M., Saboret, L., SchroedterHomscheidt, M., and Wald, L.: Fast radiative transfer parameterisation for assessing the surface solar irradiance: The Heliosat-4 method, Meteorol Z, 26, 33-57, https://doi.org/10.1127/metz/2016/0781, 2017.

Rebmann, C., Kolle, O., Heinesch, B., Queck, R., Ibrom, A., and Aubinet, M.: Data Acquisition and Flux Calculations, in: Eddy Covariance, edited by: Aubinet, M., Vesala, T., and Papale, D., Springer Netherlands, Dordrecht, 59-83, https://doi.org/10.1007/978-94-007-2351-1 3, 2012. 
Reichstein, M., Falge, E., Baldocchi, D., Papale, D., Aubinet, M., Berbigier, P., Bernhofer, C., Buchmann, N., Gilmanov, T., Granier, A., Grunwald, T., Havrankova, K., Ilvesniemi, H., Janous, D., Knohl, A., Laurila, T., Lohila, A., Loustau, D., Matteucci, G., Meyers, T., Miglietta, F., Ourcival, J.-M., Pumpanen, J., Rambal, S., Rotenberg, E., Sanz, M., Tenhunen, J., Seufert, G., Vaccari, F., Vesala, T., Yakir, D., and Valentini, R.: On the separation of net ecosystem exchange into assimilation and ecosystem respiration: review and improved algorithm, Global Change Biol, 11, 1424-1439, https://doi.org/10.1111/j.1365-2486.2005.001002.x, 2005.

Richardson, A. D., Mahecha, M. D., Falge, E., Kattge, J., Moffat, A. M., Papale, D., Reichstein, M., Stauch, V. J., Braswell, B. H., Churkina, G., Kruijt, B., and Hollinger, D. Y.: Statistical properties of random CO2 flux measurement uncertainty inferred from model residuals, Agricultural and Forest Meteorology, 148, 38-50, https://doi.org/10.1016/j.agrformet.2007.09.001, 2008.

Saby, N. P. A., Arrouays, D., Antoni, V., Lemercier, B., Follain, S., Walter, C., and Schvartz, C.: Changes in soil organic carbon in a mountainous French region, 1990-2004, 24, 254-262, https://doi.org/10.1111/j.1475-2743.2008.00159.x, 2008.

Sanderman, J., Hengl, T., and Fiske, G. J.: Soil carbon debt of 12,000 years of human land use, Proc Natl Acad Sci USA, 114, 9575-9580, https://doi.org/10.1073/pnas.1706103114, 2017.

Smith, P., Soussana, J., Angers, D., Schipper, L., Chenu, C., Rasse, D. P., Batjes, N. H., Egmond, F., McNeill, S., Kuhnert, M., Arias-Navarro, C., Olesen, J. E., Chirinda, N., Fornara, D., Wollenberg, E., Álvaro-Fuentes, J., Sanz-Cobena, A., and Klumpp, K.: How to measure, report and verify soil carbon change to realize the potential of soil carbon sequestration for atmospheric greenhouse gas removal, Glob Change Biol, 26, 219-241, https://doi.org/10.1111/gcb.14815, 2020.

VandenBygaart, A. J. and Angers, D. A.: Towards accurate measurements of soil organic carbon stock change in agroecosystems, Can. J. Soil. Sci., 86, 465-471, https://doi.org/10.4141/S05-106, 2006.

Webb, E. K., Pearman, G. I., and Leuning, R.: Correction of flux measurements for density effects due to heat and water vapour transfer, Q.J Royal Met. Soc., 106, 85-100, https://doi.org/10.1002/qj.49710644707, 1980.

Weiss, M. and Baret, F.: S2toolbox Level 2 Products: Lai, Fapar, Fcover, 2016.

White, J. W., Hunt, L. A., Boote, K. J., Jones, J. W., Koo, J., Kim, S., Porter, C. H., Wilkens, P. W., and Hoogenboom, G.: Integrated description of agricultural field experiments and production: The ICASA Version 2.0 data standards, Computers and Electronics in Agriculture, 96, 1-12, https://doi.org/10.1016/j.compag.2013.04.003, 2013. 